\title{
The Water for Climate Comfort in Architecture
}

\author{
Paola De Joanna
}

\begin{abstract}
As answer to climate change and to new and growing demands of temperature and humidity comfort in housing, it follows the increasing of air conditioning technologies; this evolutional trend involves high energy consumption. The proposed work is oriented to analyze traditional and innovative techniques for cooling indoor and outdoor air by the use of water.

In the Mediterranean traditional architecture the cooling techniques are mainly based on the principle of water evaporation, this purpose is achieved through the introduction of water into the environment, by means of various systems: stagnant water in lakes and basins, or water in motion with fountains, waterfalls, splashes, etc.

Over the time, traditional buildings have been conditioned by these techniques for cooling through the use of water up to reach complex and sophisticated architectural designs.

Starting from this heritage, innovative systems have been developed to reach higher performance to integrate building systems, both traditional as well as moderns, in order to ensure a significant reduction of energy consumption.
\end{abstract}

Keywords - Traditional architecture, water, comfort, energy.

\section{INTRODUCTION}

The increasing demand for comfort is more and more conflicting with the need of saving energy; one third of the world population lives in areas where the climate conditions exceed the limit level of the comfort zone and the number of people who use air conditioning systems is quickly becoming bigger and bigger. In Italy a large part of the housing stock was constructed during the 60 's and 70's without any attention at thermal comfort performance, of consequence the demand for air-conditioning was faced with the use of electric systems that caused more and more often a spike in electricity consumption that creates costly imbalances in the energy policy of our country. Starting from 2002 the Directive of the European Parliament and of the Council imposes that European government policies are oriented toward the reduction of energy consumption; from 2006, the energy certification of buildings is obligatory and are encouraged the lines of research for developing alternative systems for cooling/heating with low power consumption and technologies for saving thermal comfort.

In this frame it is useful to treasure of the solutions and devices of traditional building techniques for cooling together with those of more recent experiments that use water with low energy consumption. The repertoire of building elements, forms, techniques and tools that exploit the use of water in the

Department of Architecture, Federico II University of Naples (IT) DiARC. architectural production is vast and impressive, and above all it is an expression of the material culture of places and social realities.

In the Mediterranean building tradition the use of water is often an expression of symbolic values but it also become devices to meet the need for supply and collection of water resources, for therapeutic purposes, sanitary, mechanical and, not least, to the need of conditioning the building microclimate. The cooling in the Mediterranean traditional building is based mainly on systems that exploit natural phenomena: the sun protection, ventilation and evaporation.

If we observe the techniques of traditional air conditioning, in absence of non-renewable energy, you find a large, sometimes rudimentary, repertoire consolidated in the traditional architecture. To prevent overheating it is necessary to contain the incident solar radiation directly on the surfaces of the building for an extended period. For this reason the traditional buildings are often characterized by protrusions that produce shading of the more sunny facades. Furthermore the induction of air movement is used for the control of the temperature by: locating the openings so as to facilitate air flows cross, disposing interspaces for ventilation of the facades, so as to allow the removal of superheated air, organizing openings on the roof to facilitate the escape of hot climbing flows. An additional and effective method for cooling of living spaces exploits the phenomenon of water evaporation.

\section{II.COOLING TECHNIQUES EMPLOYING THE WATER'S EVAPORATION}

In an environment the introduction of water that can evaporate determines an increase in humidity, but simultaneously produces a significant lowering of the relative temperature; by this way we can mainly distinguish two distinct modes of cooling: by evaporation direct and indirect. In architecture the traditional cooling techniques, based on the principle of evaporation, have been substantially resolved with the introduction of water in the environments, stagnant in tanks or ponds, or on the move with fountains, waterfalls, sprays etc .; the evaporation of water in confined environments is the technique that was used the most remote times. Additional devices are often used to optimize these systems such as the induction of air motions, shaded areas, the planting of particular species arboreal capable of integrating the heat exchange ${ }^{1}$. This phenomenon was already known from Romans, who put water in clay jars which sweated and

\footnotetext{
${ }^{1}$ In hot and dry climates the hot air has a low humidity percentage and therefore can produce an appreciable evaporation of the water, thus the temperature decreased and the comfort degree is optimized.
} 
evaporating, made it cool the surrounding air; in the Arab wet or porous skins full of water.

world they used to put in front of windows curtains, constantly

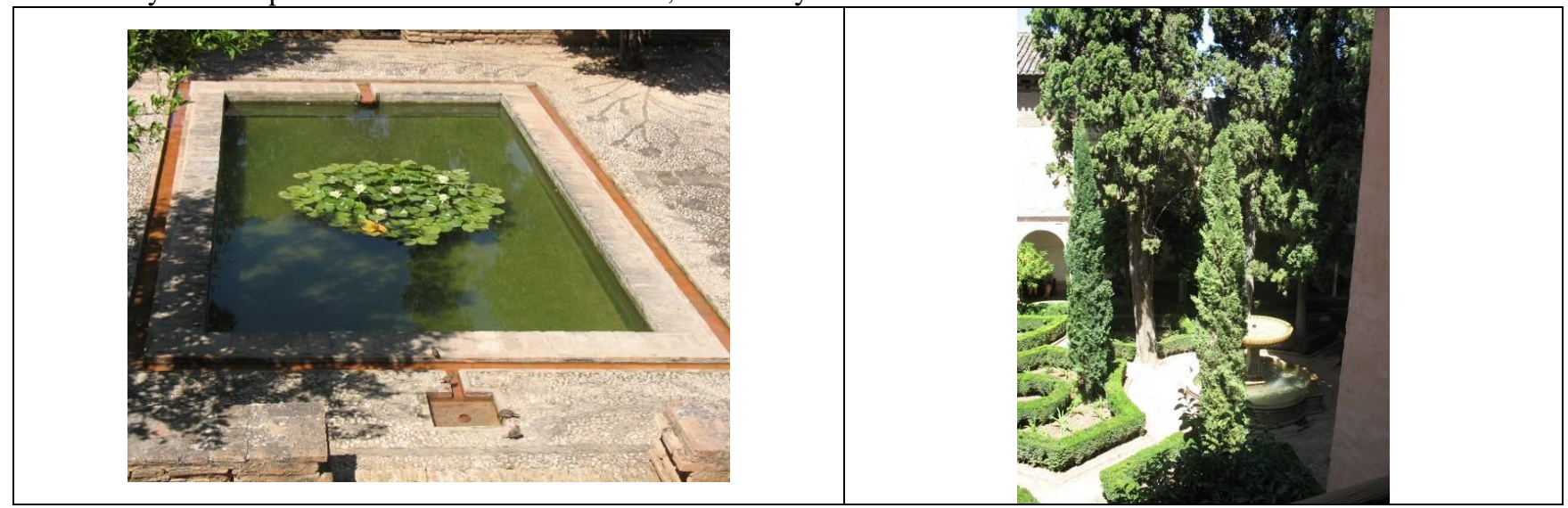

Fig. 1: Alhambra Gardens, Granada

The application of such systems for cooling has, in many cases, conditioned the evolution of the building tradition so that different forms and ways of living have been developed. For instance the distribution of environmental units and their functions has been influenced from the possibility of air conditioning in different spaces; in hot countries people have the habit to place representative spaces or living at the level of the courts where the presence of pools, fountains and vegetation makes these spaces preferable to those of higher plans which in other climates have different or better consideration.

Also the structural characteristics of the technical elements are affected by the use of water for the control of the microclimate:

- - the spaces distributed along the perimeter of courts and gardens are usually open towards the inside and are blind to the outside, the openings are located in the upper part to increase the shaded surface in order to facilitate the convective motion of the hot air;

- - in wet spaces, the lower surface of the shell has often plaster decorations that expand the exchange surface so that to favour the removal of any condensate in summit parts;

- - in the open spaces you can find that the space is articulated in different levels which have small differences in height to induce the water runoff so that to increase the exchange air/water;

- - in external paving are used materials permeable and porous allowing water evaporation from the soil.

Furthermore, the presence of water, beyond its physical property of mitigating the internal microclimate, involves a psychological effect so that the only acoustic or visual perception can affect the feeling of thermo-hygrometric comfort. Other cooling techniques in traditional architecture were developed to integrate those with water evaporation; we mean the building of cooling towers and the exploitation of evapo-transpiration of plants.

The cooling tower (badgir) is based on the use of tanks from which, through holes, small drops of water seep, these falling drops combine with the outside air and cool it; otherwise the air from the ventilation towers is conveyed in the underground plants that supply water to the wells (qanat ${ }^{2}$ ) where it cools.

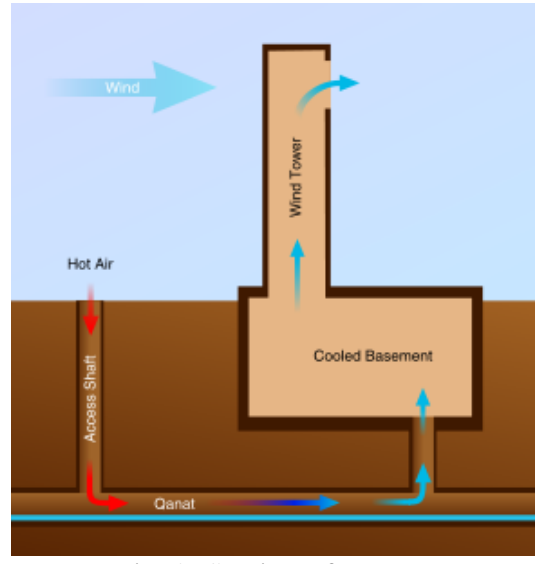

Fig. 2: Section of a qanat

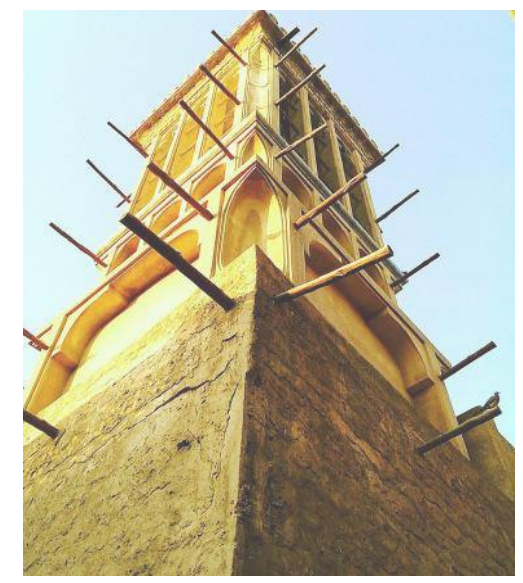

Fig. 3:Traditional wind tower in Old Dubai

\footnotetext{
${ }^{2}$ Cooling towers are also used in combination with a qanat (underground canal). The tower has an open side away from the direction of the prevailing wind (the tower's orientation can be adjusted by directional ports). The pressure differential between the opposite sides of the tower, forces the air into the passage on the other side. The hot air is brought down into the qanat tunnel where it is cooled thanks to the contact with the cold water running through the qanat. The cool air flows through the building so that to decrease the structure's temperature.
} 


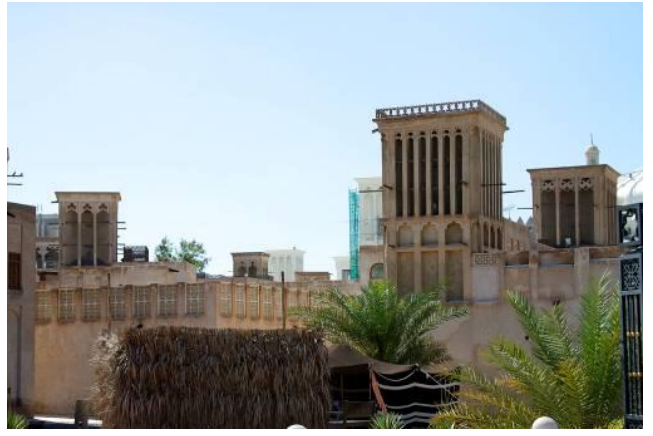

Fig. 4: Dubai's Bastakia Quarter

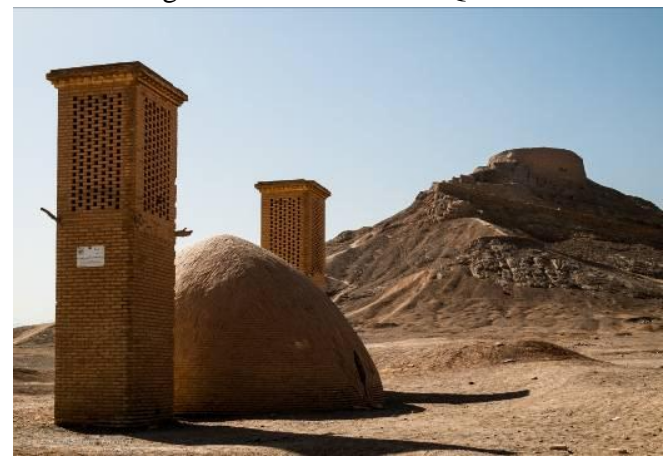

Fig. 5: Ice Chamber and Tower of Silence, Yazd

The evapo-transpiration of plants can provide a significant cooling effect on the air thanks to the transfer of water vapour from the surface of the plant to the surrounding environment; different tree species have different potential for evaporation that vary according to the size of the plant, the contribution of lymph that they need and the climate in which they develop. Careful selection of plantings can therefore produce a significant lowering in temperature, thus contributing to passive climate conditioning.

The indirect cooling by evaporation is based on the principle to avoid water contact with the air in order not to increase the percentage of wetness. This system, for example, is the evaporative cooling in two stages: the air cooled by direct evaporation is used for cooling a section of the device (air-air exchanger). This exchange unit is used for cooling of new air that is introduced into the environment.

\section{NEW APPLICATIONS IN AIR CONDITIONING BY THE EMPLOY OF WATER}

Starting from traditional experiences, the technological research in this area has come to the development of innovative systems based on the principle of air cooling by evaporation; systems that offer a high performance and that can integrate various building systems in addition to ensuring a significant reduction of the energy consumption.

Devices for direct cooling:

The coolers, which have very low operating costs, are devices in which the low speed fans push the air through a honeycomb package in pure cellulose, constantly sprayed with water, by an automatic system with recovery tank; this system determines an effective exchange between air and water. Generally the performance of this type of machines is not very high and you cannot have the humidity control in the environments.

Evaporative systems, the artificial fog, is produced by atomising stations that spread water droplets of a few microns; the very fine mist evaporates instantly lowering the temperature of the surrounding air to some degrees, thus allowing the use of outdoor spaces, covered or uncovered, even in moments of greatest heat.

Devices for cooling indirect

Roof spray, the outer surface of the roof is kept wet using atomizers, the heat of the cover is thus dissipated by the continuous evaporation and the underlying volume is cooled with an energy saving up to $25 \%$. This system is effective in particular for the cooling of large environments (industrial warehouses, depots of food, etc.) where there is adequate water availability.

Roof pond, the hedge is not isolated and it is topped by a shaded tank. The continuous evaporation of water (day and night) lowers the temperature of the interior space without increasing humidity levels. Anyway this technique involves a high consumption of water and it can be applied only to last levels under the roof (which must be calculated to withstand high loads)

\section{Solar cooling}

The solar cooling is the most interesting answer to the objective of passive cooling, a recent survey conducted from International Energy Agency shows that the estimated number of solar cooling installation worldwide was about 1200 systems in $2014^{3}$. If compared to conventional technology solar cooling systems have been proven to be favourable in saving energy. The energy savings mostly depend on factors such as: the solar fraction needed to drive the cooling device and the electricity demand for auxiliary components (fans in the cooling tower and pumps in the hydraulic circuits. The cost saving during operation very much depends on the boundary conditions: high annual solar radiation, duration of cooling season, other heat loads such as for sanitary hot water and/or process heating increase the usefulness of the solar system.

A solar cooling system is composed of an adsorption chiller, a solar thermal unit (a flat plate collector and a hot water storage tank), a solar chimney and a cooling channel.

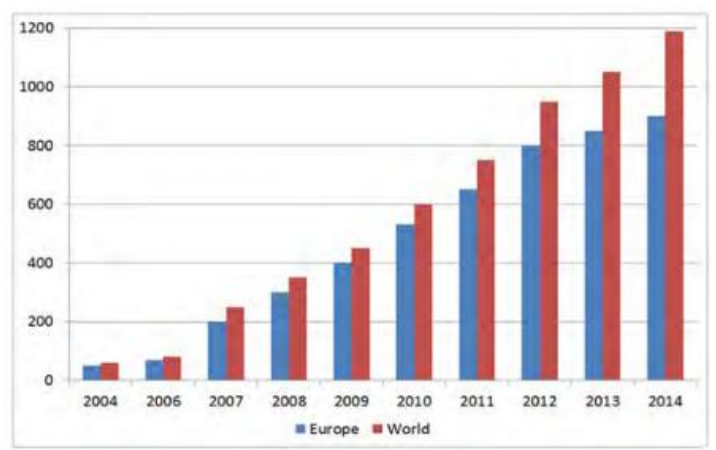

Fig. 6: Estimated number of solar cooling installations worldwide. (Source : TECSOL/SOLEM)

\footnotetext{
${ }^{3}$ IEA-SHC Annual Report 2015, Technology Collaboration Programme on Solar Heating and Cooling, Edited by Pamela Murphy SHC Secretariat.
} 


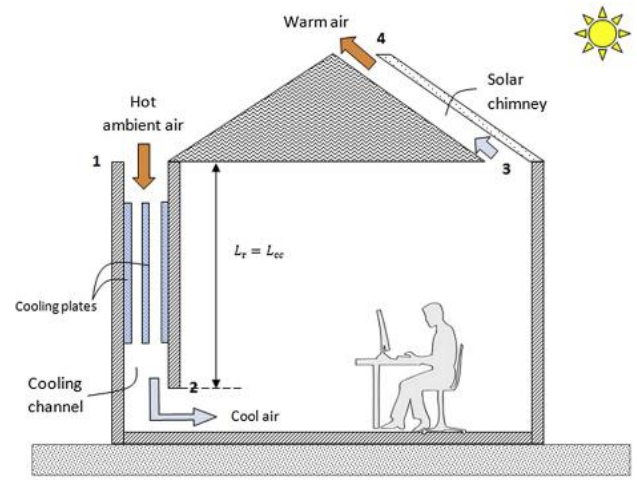

Fig. 7: Schematic of the room and the solar cooling system ${ }^{4}$

The solar chimney is a glass surface south-oriented and an absorber wall. The air inside the chimney is heated by the solar radiation, which passes through the glass and is absorbed by the wall. This creates a chimney effect that sucks the air into the room and from outside through the cooling channel where its temperature decreases thanks to the chilled water produced in the adsorption chiller ${ }^{5}$. The required heat source for the operation of the chiller is provided by solar energy. Solar cooling technology is a complex technology and requires much more standardisation for the coupling of key components and the development of robust, standardised solutions in the future (Mugnier D., Uli J., 2012).

Firstly you require putting into quality procedures for designing, commissioning, monitoring, operating and maintaining solar heating and cooling systems in order to overcome the barriers that limit the development of the market in the sector. This will contribute to increase the awareness and acceptance of the technology and trust in the market potential of solar heating and cooling systems.

\section{Challenges for solar cooling}

Nowadays components for SAC technology are advanced and many installations have been realized. It is proved that this technology is able to produce significant energy savings, anyway the financial risk for parties involved in SAC business is still too high. Some actions are required to reduce this risk. Currently there are no international ISO/EN standards or specific rules for solar cooling; they could provide the development of systematic requirements for quality assurance and standards for SAC systems and also could be the basis for allocating funding to support market development.

In order to compensate this lack two specific Tasks in Technology Collaboration Programme on Solar Heating and Cooling of IEA have been activated (Task 43 and Task 49), actually main issue of this tasks are:

- Draft "Global Solar Certification Scheme" for inspiration for new and existing national certification schemes;
- The "Global Solar Certification Network" has been established with the main aim of organizing mutual accept of test reports and inspection reports by existing national and regional certification schemes;

- Demonstration Projects and SHIP Database - 188 SHIP applications that have been surveyed have sufficient data to be published on ship - plants-info.

\section{REFERENCES}

[1] Azadeh Jafari, Amin Haghighi Poshtiri (2016), Passive solar cooling of single-storey buildings by an adsorption chiller system combined with a solar chimney, Journal of Cleaner Product ion, Elsevier.

[2] Henning, H.M., Motta M., and Mugnier, D. (2013), Solar Cooling Handbook: A Guide to Solar Assisted Cooling and Dehumidification Processes, Walter de Gruyter \& Co.

https://doi.org/10.1515/9783990434390

[3] Jakob, U. (2009), Solar Cooling in Europe, Proceedings of the ausSCIG Conference 2009, CSIRO, Newcastle, Australia, 19 May 2009.

[4] Malouf, C., Wurtz, E. (2007), Rafraichissement solaire: Une experimentation a chambery. RPF - la Revue Pratique du Froid 7/ 2007 (Pag. 62 - 68).

[5] Mottura, G., Pennisi, A., Marchesini Viola P. (2008), L'Architettura dell'Acqua, Maggioli Editori, 2008.

[6] Mugnier, D. (2012), Solar Thermal Energy for cooling and refrigeration: status and perspectives, Proceedings of the First Saudi Renewable Energy Conference \& Exhibition - SAREC \& E 2012, Dahran, South Arabia, 20.02.2012.

[7] Mugnier, D. (2011), Quality Assurance and Support Measures for Solar Cooling - Task description and Work plan, http://task48.ieashc.org/documents.

[8] Mugnier, D., Uli, J. (2012), Keeping cool with the sun, International Sustainable Energy Review, Volume 6, Issue 1, 2012

[9] Murphy, P. et al., IEA Solar Heating and Cooling Programme Strategic Plan 2009- 2013.

[10] Roaf, S., Horsley, A., and Gupta,R. 2004, Closing the Loop: Benchmarks for Sustainable Buildings, RIBA Publications, London.

[11] Schiaffonati, F.e Mussinelli, E. (2008), Il Tema dell'Acqua nella Progettazione Ambientale, Maggioli Editore.

\footnotetext{
${ }^{4}$ Azadeh Jafari, Amin Haghighi Poshtiri (2016),

5 Solar cooling (and especially sorption chillers) uses environmentally friendly refrigerants (water or ammonia) with very low electricity demand.
}

\footnotetext{
${ }^{6}$ The Global Solar Certification Network will start operation during 2016 (supported by new IEA SHC Task 57)
} 
International Conference on Civil, Architecture and Sustainable Development (CASD-2016) Dec. 1-2, 2016 London(UK)

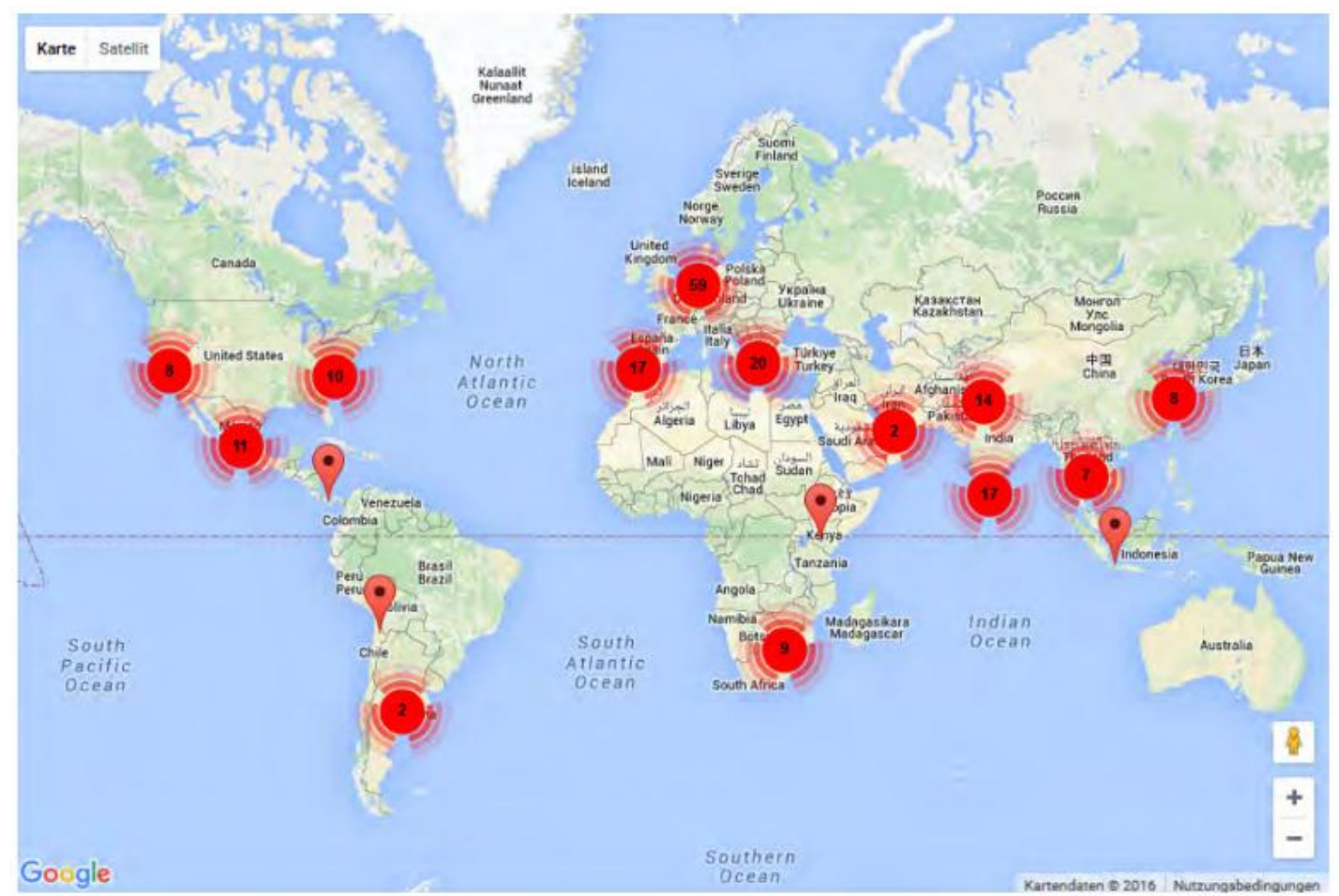

Fig. 8: Location of reported SHIP applications 